\title{
Phenotypic Methods for the Detection of Metallo- Beta-Lactamase Production by Gram-negative Bacterial Isolates from Hospitalized Patients in A Tertiary Care Hospital in India
}

\author{
K. Sreeja Vamsi ${ }^{1}$ (D) S. Rama Moorthy ${ }^{2 *}$ (D) T.S. Murali ${ }^{3}$, Mary Hemiliamma ${ }^{4}$, \\ Y. Raja Rathna Reddy ${ }^{\mathbb{D}}$, B. Rama Chandra Reddy ${ }^{\mathbb{D}}$ and J. Sunil Kumar ${ }^{4} \mathbb{D}$ \\ ${ }^{1}$ Department of Microbiology, Manipal Academy of Higher Education, Manipal - 576 104, Karnataka, India. \\ ${ }^{2}$ Department of Microbiology, Palamur Biosciences Pvt.Ltd., Mahabubnagar - 509 382, Telangana, India. \\ ${ }^{3}$ Department of Biotechnology, Manipal Academy of Higher Education, Manipal - 576 104, Karnataka, India. \\ ${ }^{4}$ Department of Microbiology, SVS Medical College, Mahbubnagar - 509 001, Telangana, India.
}

\begin{abstract}
Drug resistant bacteria are a global health concern owing to the high morbidity and mortality they can cause, especially in countries such as India. Gram-negative bacteria, including Enterobacteriaceae, Pseudomonas, and Acinetobacter, are primarily responsible for expanding the scope of drug resistance. These antibiotic-resistant pathogens are particularly associated with serious infections in hospitals. The production of carbapenemase by gram-negative bacteria appears to be the major reason for their resistance to carbapenems. The study was a prospective study done from March 2018 to December2020. All the carbapenem-resistant isolates from various clinical samples were further tested for the production of carbapenemases/metallo-beta-lactamases production by various phenotypic tests like carbaNp, Imipenem-EDTA combined disc synergy test, Double-disc synergy test and E-test methods. Of all carbapenem-resistant gram-negative bacteria isolated from patients in a hospital in India, 237 (88.1\%) carbapenemase producers were identified, among which 217 (91.5\%) were metallo-betalactamase (MBL) producers. Therefore, the detection of $\mathrm{MBL}$ producers is important for preventing their infectious spread. The present study revealed that most MBL producers were isolated from patients of $0-9$ to years of age (63.9\%). The double-disc synergy test (DDST) and E-test MBL strips were more sensitive than the combined disc test in detecting MBLs. Because the DDST was the simplest and most effective method, it can be used for the routine laboratory screening of MBL producers in hospitals.
\end{abstract}

Keywords: Carbapenems,Gram negative bacilli,Metallo- beta- lactamase,Imipenem-EDTA combined disc synergy test,Double-disc synergy test, E-test method

*Correspondence: ram.murthy@palamurbio.com

(Received: July 07, 2021; accepted: September 22, 2021)

Citation: Vamsi KS, Moorthy SR, Murali TS, et al. Phenotypic Methods for the Detection of Metallo-Beta-Lactamase Production by Gram-negative Bacterial Isolates from Hospitalized Patients in A Tertiary Care Hospital in India. J Pure Appl Microbiol. 2021; 15(4):2019-2026. doi: 10.22207/JPAM.15.4.23

(C) The Author(s) 2021. Open Access. This article is distributed under the terms of the Creative Commons Attribution 4.0 International License which permits unrestricted use, sharing, distribution, and reproduction in any medium, provided you give appropriate credit to the original author(s) and the source, provide a link to the Creative Commons license, and indicate if changes were made. 


\section{INTRODUCTION}

The expansion and spread of multi drug-resistant gram-negative bacteria (GNB) is a major public health concern worldwide owing to the high morbidity and mortality that can result from infections by such pathogens, especially in India. ${ }^{1}$ These non-susceptible bacteria are particularly associated with serious hospitalacquired infections, also known as nosocomial infections. ${ }^{1}$

GNB, including the Enterobacteriaceae, Pseudomonas, and Acinetobacter, are primarily responsible for expanding drug resistance and are associated with serious nosocomial infections. According to a World Health Organization survey, approximately $7 \%$ of hospital patients in developed countries will acquire a nosocomial infection at least once at any given time. ${ }^{2}$ However, the prevalence in India is more frightening, ranging from $10 \%$ to $83 \%$, with distinctive types of nosocomial infections. ${ }^{2}$

The origins of nosocomial infections can be from external (e.g.,various substances, crowds, foodstuff, water, and ventilation in the hospital) or internal sources (e.g., hospital devices, hospital staff, etc.), and even the patient's own skin flora can become opportunistic owing to changes in the immune system after surgery. ${ }^{3}$ In India, nosocomial infections are mostly caused by microorganisms with antimicrobial resistance, which is mainly attributed to the overuse of antibiotics and the deficit of new effective ones, all of which can lead to significant financial burden and mental stress to both the patients and their family members. Owing to the paucity of available therapeutic options, antimicrobial resistance has become one of the greatest public health concerns, with the incidence of complications associated with multidrug-resistant GNB increasing worldwide.

Beta-lactam antibiotics, such as the carbapenems, are generally used as the drugs of last resort for the management of infections induced by multidrug-resistant GNB. Being broad-spectrum antibiotics, carbapenems are used for the treatment of several types of serious infections. ${ }^{3}$ However, pathogens with resistance to this class of drugs have increased significantly in recent years. ${ }^{3}$
Resistance to carbapenems is mediated through various mechanisms in bacteria, including the production of beta-lactamases (carbapenemases) that hydrolyze the antibiotics, the generation of changes to the outer membrane porins that block the entry of antibiotics, and active pumping of the antibiotics out of the cell via complex efflux pumps. Among these, carbapenemase production appears to be the main reason for carbapenem resistance in GNB. ${ }^{4}$ Carbapenemases have the ability to hydrolyze pencillins, cephalosporins, monobactams, and carbapenems, there by limiting the treatment options. There are two major groups of these enzymes, which differ according to their hydrolytic mechanism and amino acid sequence at the active site: serine beta-lactamases and metallo-betalactamases (MBLs).

The latter group comprises the class B lactamases, which can be inhibited by metal chelators such as ethylenediamine tetra acetic acid (EDTA) and have zinc in their active sites. These MBLs arebroad-spectrum antibiotics with hydrolytic activity. In GNB, the MBL-encoding genes are carried by mobile genetic elements. The first plasmid-borne MBL gene was reported in Pseudomonas aeruginosa in Japan in $1991 .{ }^{5}$ In India, an MBL-producing $P$. aeruginosa strain was first reported in 2002 by Navaneeth et al. ${ }^{6}$ Since then, reports on the prevalence of MBL producers have been made in many countries, including India. ${ }^{6}$

Although genotyping with the polymerase chain reaction (PCR) has always been the gold standard test method for the detection of $\mathrm{MBL}$ genes, it is not routinely used because of its high cost and is usually restricted to research purposes. The majority of diagnostic laboratories still rely mostly on culture-based phenotypic tests for the rapid detection of MBL activity. The early detection of MBL-producing organisms is critical, as it allows for the prompt use of appropriate antibiotics to effectively control the infection. In this study, we aimed to identify MBL-producing GNB in a hospital in India and to compare and assess different phenotypic methods for their detection as well as createan antibiogram that can be used to guide physicians in their choice of correct antibiotics to use and control of hospital infections. 


\section{MATERIALS AND METHODS}

\section{Study site and sampling criteria}

This study was conducted at the Department of Microbiology, SVS Medical College and Hospital in Mahabubnagar, Telangana, India from March 2018 to December2020.Institutional ethical clearance was obtained before the start of the study (SVSMC/IEC Approval No.05/2018-623). Of 2890 clinical samples processed, 1093 showed GNB growth, with 269 being carbapenem-resistant strains. These 269 isolates were included in this study.

The inclusion criteria for the study were as follows: GNB, such as Escherichia coli, Klebsiella, Pseudomonas spp., and Acinetobacter spp., isolated from various clinical samples from patients admitted to the hospital. The exclusion criteria were organisms other than E.coli, Klebsiella, Enterobacter, Acinetobacter, and Pseudomonas spp. and specimens from the out patient department.

All isolates were collected under strict aseptic conditions and processed according to standard laboratory protocols. The strains were identified on the basis of their colony morphology, staining properties, and various biochemical reactions as well as through use of the Vitek 2 system.

\section{Antibiotic susceptibility testing}

The sensitivity of the isolates to various antimicrobials was tested using the Kirby-Bauer disc diffusion method according to Clinical Laboratory Standards Institute guidelines (CLSIM100-S21). ${ }^{7}$ The antibiotic discs used were

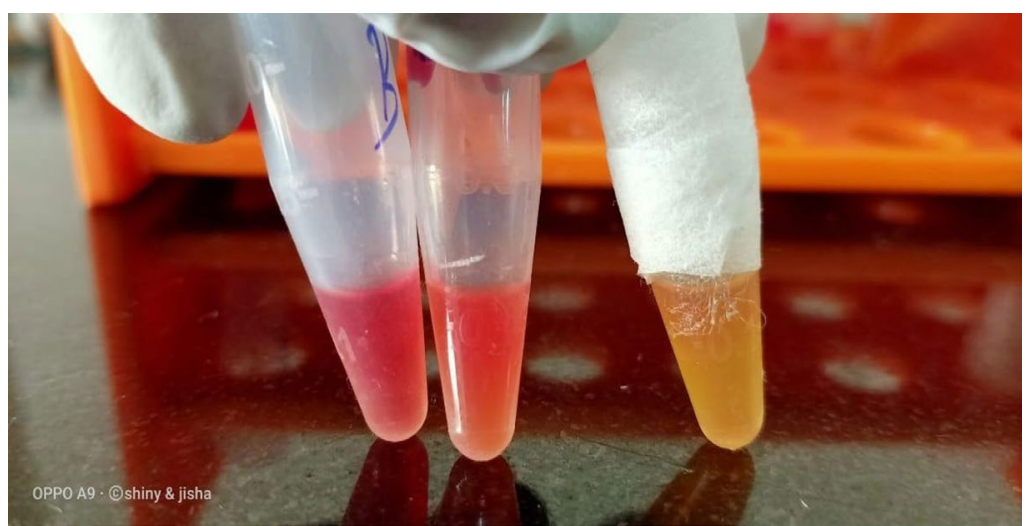

Fig. 1. showing production of carbapenems yellow colour indicate the organism is producing carbapenemase.

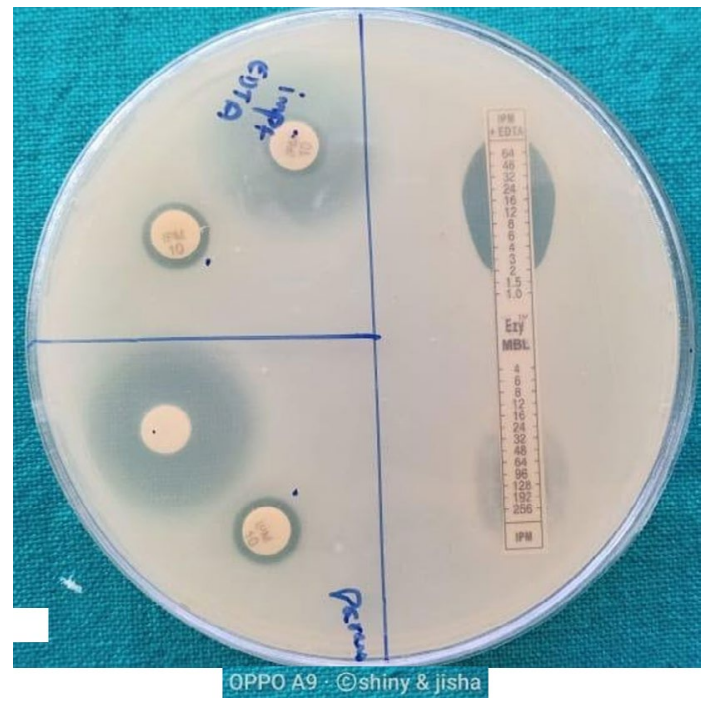

Fig. 2. MBL detection by 3 phenotypic methods. imipenem $(10 \mu \mathrm{g})$, ampicillin $(10 \mu \mathrm{g})$, amikacin $(30 \mu \mathrm{g})$, ecefotaxime $(30 \mu \mathrm{g})$, cephalexin (30 $\mu \mathrm{g})$, ceftazidime $(30 \mu \mathrm{g})$, meropenem (10 $\mu \mathrm{g})$, ertapenem $(10 \mu \mathrm{g})$, doripenem $(10 \mu \mathrm{g})$, and piperacillin-tazobactam $(100 / 10 \mu \mathrm{g})$, (all from HiMedia, Mumbai, India). The organisms that were resistant to imipenem and meropenem were further tested for carbapenemase production using the Vitek 2 system.

\section{Detection of carbapenemase production}

An in-house Carba NP test produced according to CLSI guidelines was used for the detection of carbapenemases. This test is quick, simple, and cost effective to use, as itr equires minimal preparation time. In brief, 2-3 loops full of bacterial colonies were added to $200 \mu \mathrm{L}$ of sterile water in a mini centrifuge tube (marked A) to make a concentrated inoculum, following which 
$100 \mu \mathrm{L}$ was transferred to another mini centrifuge tube (marked B). Then, $100 \mu \mathrm{L}$ of solution $\mathrm{A}$ (10 $\mathrm{MZnSO}_{4}$ and $0.05 \%$ phenol red, $\mathrm{pH} 7.8$ ) was added to tube $A$, and $100 \mu \mathrm{L}$ of solution $B(1$ $\mathrm{mL}$ of solution $A$ and $6 \mathrm{mg}$ of imipenem powder) was added to tube $B$. Both tubes were incubated for $2 \mathrm{~h}$ to allow a change of color from red to yellow or orange, which indicates the presence of carbapenemase. The carbapenemase producers were then tested for MBL production (Fig. 1). ${ }^{8}$

Metallo-beta-lactamase detection methods Imipenem-EDTA combined disc synergy test

Two imipenem (10g) discs were spaced 20 $\mathrm{mm}$ apart atop a lawn culture of the test organism. One of the discs was then covered with $4 \mu \mathrm{L}$ of EDTA and the plate was incubated at $37^{\circ} \mathrm{C}$ for 24 $h$. Following incubation, the inhibition zones of the discs with imipenem alone and imipenem-EDTA combined were measured. MBL positivity was defined as a $7 \mathrm{~mm}$ increase in the inhibition zone of the disc containing imipenem-EDTA relative to that of the disc with imipenem alone. ${ }^{9}$

\section{Double-disc synergy test}

An imipenem $(10 \mu \mathrm{g})$ disc was placed in the center of the plate a top a lawn culture of the test organism, and a sterile blank disc was placed $20 \mathrm{~mm}$ away from it. Then, the blank disc was covered with $10 \mu \mathrm{L}$ of $0.5 \mathrm{M}$ EDTA $(750 \mu \mathrm{g})$. Enhancement of the zone of inhibition in the area between the imipenem and EDTA discs in comparison with the zone of inhibition on the far side of the drug was interpreted as a positive result for MBL production. ${ }^{10}$

\section{E-test method}

Single strips impregnated with a concentration gradient of imipenem (4-256 $\mu \mathrm{g} /$ $\mathrm{mL}$ ) on one end and that of imipenem (1-64 $\mu \mathrm{g} /$ $\mathrm{mL}$ ) fused with a stable concentration of EDTA on the other end were placed a top lawn cultures of the test organisms in culture plates. An 8-fold increase in the ellipse of imipenem and EDTA indicated the presence of MBL (Fig. -2). ${ }^{10,11}$

\section{Statistical analysis}

The data were entered into Microsoft Excel and a tabular format was used wherever necessary. Evaluation of the data was performed using SPSS version 20 and Graph Pad Prism version 6.0.Positive and negative predictive values were also computed.

Table 1. Distribution of carbapenems producers and MBL producers in different isolates

\begin{tabular}{lccc}
\hline Organisms & CRGNB & $\begin{array}{c}\text { Carbapenemase } \\
\text { Producers }\end{array}$ & $\begin{array}{c}\text { MBL } \\
\text { Producers }\end{array}$ \\
\hline Klebsiella Sps. & 121 & 117 & 114 \\
E. coli & 76 & 64 & 61 \\
Acinetobacter Sps. & 31 & 23 & 17 \\
Pseudomonas Sps. & 27 & 19 & 14 \\
Enterobacter Sps. & 14 & 14 & 11 \\
Total & 269 & 237 & 217 \\
\hline
\end{tabular}

Table 2. Age and Sex wise distribution of MBL producers

\begin{tabular}{lcccc}
\hline $\begin{array}{l}\text { Age } \\
\text { (years) }\end{array}$ & $\begin{array}{c}\text { No. of } \\
\text { patients }\end{array}$ & Males & $\begin{array}{c}\text { Females } \\
\%\end{array}$ & Total \\
\hline $0-9$ & 118 & 67 & 51 & $54.3 \%$ \\
$10-19$ & 11 & 9 & 2 & $5.06 \%$ \\
$20-29$ & 12 & 6 & 6 & $4.83 \%$ \\
$30-39$ & 19 & 13 & 6 & $8.7 \%$ \\
$40-49$ & 29 & 19 & 10 & $13.3 \%$ \\
$50-59$ & 2 & 2 & -- & $0.92 \%$ \\
$>60$ & 26 & 15 & 11 & $11.9 \%$ \\
Total & 217 & 131 & 86 & $100 \%$ \\
\hline
\end{tabular}

\section{RESULTS}

Of the 2890 clinical samples tested, 1093 were found to contain GNB, among which 24.6\% (or 269 organisms) were resistant to both imipenem and meropenem. Of the 237 (88.1\%) GNB that were carbapenemase producers, 217 (91.5\%) produced MBLs (Table 1 ).

The most predominant species among these carbapenem-resistant isolates was Klebsiella sp. (121,44,99\%), followed by $E$. coli $(76,28.25 \%)$, Acetobacter spp. $(31,11.5 \%)$, Pseudomonas 
Vamsi et al. | J Pure Appl Microbiol | 15(4):2019-2026 | December 2021 | https://doi.org/10.22207/JPAM.15.4.23

Table 3. Prevalence of MBL producers in different samples

\begin{tabular}{|c|c|c|c|c|c|c|}
\hline Samples & Klebsiella & E.coli & Acinetobacter & Pseudomonas & Enterobacter & Total \\
\hline BAL & 5 & -- & - & 1 & - & 6 \\
\hline BLOOD & 27 & 14 & 1 & 3 & 3 & 48 \\
\hline ET & 33 & 15 & 12 & 5 & 3 & 68 \\
\hline PUS & 9 & 8 & 2 & 4 & 1 & 24 \\
\hline SPUTUM & 12 & - & - & - & - & 12 \\
\hline STOOL & 11 & 8 & - & - & 1 & 20 \\
\hline CSF & 2 & - & 1 & - & 1 & 4 \\
\hline URINE & 11 & 13 & 1 & - & 1 & 26 \\
\hline BODY FLUIDS & 4 & 3 & - & 1 & 1 & 9 \\
\hline TOTAL & 114 & 61 & 17 & 14 & 11 & 217 \\
\hline
\end{tabular}

Table 4. antibiotic resistance pattern of carbapenemase producing bacteria

\begin{tabular}{lccc}
\hline Drugs & Carbapenemase & Resistance GNB & Percentage \\
\hline Amikacin & 217 & 156 & $71.8 \%$ \\
Ceftrazidime & 217 & 217 & $100 \%$ \\
Ceftriaxone & 217 & 217 & $100 \%$ \\
Cefepime & 217 & 217 & $100 \%$ \\
Ciprofloxacin & 217 & 211 & $97.71 \%$ \\
Cefoxitin & 217 & 217 & $100 \%$ \\
Tigicycline & 217 & 9 & $4.14 \%$ \\
Colistin & 217 & 8 & $3.68 \%$ \\
Pipercicllin and & 217 & 217 & $100 \%$ \\
Tazobactam & & & \\
\hline
\end{tabular}

spp. (27,10\%), and Enterobacter spp. (14,5.2\%). Klebsiella spp. also made up the highest proportion of carbapenemase producers $(117,59.5 \%)$, followed by $E$. coli $(64,27.0 \%)$, Acinetobacter sp. (23, 10\%), Pseudomomonas spp. (19,8\%), and Enterobacter spp. (14, 5.9\%). The number of MBL-producing GNB was as follows: 114 (97.3\%) Klebsiella pneumoniae isolates out of the 117 Klebsiella sp. isolated; 61 (95.3\%) out of the $64 E$. coli isolates; 17 (73.9\%) out of the 23 Acinetobacter isolates; and 14 (73\%) out of the 19 Pseudomonas isolates.

In total, 131 (60.3\%) of the $217 \mathrm{MBL}$ producing isolates were from male patients and 86 (39.63\%) from female patients. Most of the MBLproducing isolates were isolated from patients of $0-9$ years of age $(54.3 \%)$, followed by those of age $40-49$ years $(13.3 \%)$ and 60 years $(11.9 \%)$, with the lowest number of isolates coming from patients of age $50-59$ years $(0.80 \%$ ) (Table 2 ).
Table 5. Detection of MBL by different methods

\begin{tabular}{lcc}
\hline & Positive & Negative \\
\hline Carba np test & 237 & 32 \\
DDST & 217 & 20 \\
MBL-E test & 217 & 20 \\
CDT & 211 & 26 \\
\hline
\end{tabular}

Among these $217 \mathrm{MBL}$-producing GNB, the majority were isolated from endotracheal secretions (68,31.3\%), followed by blood (48.2\%), urine (11.9\%), and pus (11.0\%). The lowest number of isolates was found in cerebrospinal fluid (1.8\%) (Table 3).

All carbapenemase organisms are $100 \%$ resistant to piperacillin and tazobactam cefoxitin cefepime ceftriaxone ceftazidime and almost $100 \%$ resistant to ciprofloxacin followed by $71.8 \%$ resistant to amikacin. Least resistance was observed for tigecycline $(4.14 \%)$ and colistin (3.68\%) (Table 4). 
The 237 carbapenemase producers were screened for their production of MBLs, where a comparison of the double-disc synergy test (DDST), combined disc test (CDT), and E-test MBL strip was made. The DDST gave the same positive results as the E-test MBL strip on 217 isolates, whereas the CDT only gave positive results for 211 isolates (Table 5).

\section{DISCUSSION}

Carbapenems, one of the most potent classes of antibiotics with broad spectrum activity, are used frequently to treat infections caused by various bacteria, especially those causing nosocomial infections. The carbapenems have a broader antimicrobial spectrum than the available combinations of penicillins and beta-lactamase inhibitors. In general, gram-positive bacteria are highly susceptible to the antibiotics imipenem, panipenem, and doripenem, whereas GNB are slightly more resistant to meropenem, biapenem, ertapenem, and doripenem. ${ }^{12-14}$

The broad-spectrum beta-lactam antibiotics are used in the treatment of multidrugresistant GNB. MBL-producing GNB exist worldwide. Our study found a $24.6 \%$ prevalence of carbapenem-resistant GNB in our ospital. In a study conducted by Hussein et al., ${ }^{15} 57.26 \%$ of the isolated strains were resistant to both meropenem and imipenem. Increase in the prevalence of the MBL producing bacteria and their rapid dissemination is quite worrisome which needs implementation of surveillance studies. ${ }^{16}$

The prevalence of MBL producers was $19.8 \%$ in our study, but this rate varied from $7 \%$ to $90 \%$ in other studies. For example, the prevalence of MBL producers in Pakistan was found to be $27.1 \%$, and these organisms are recognized to be circulating in Africa, Europe, and Australia. ${ }^{17,18}$

MBL-producing GNB are difficult to control owing to their quick and easy spread via horizontal (plasmid) transfer with in the hospital setting. This creates a barrier to infection control and treatment. Therefore, the early detection of MBL producers is crucial for preventing the spread of disease and decreasing the related mortality rates.

In this study, the DDST and E-test MBL strips were more sensitive than the CDT in detecting these pathogens, which is similar to the findings of other studies. Khosravi et al. ${ }^{19}$ showed that E-test MBL strips were $100 \%$ more accurate than $P C R$ in detecting MBL producers. Our finding that the DDST method could detect $217 \mathrm{MBL}$ producers from 237 carbapenemase producers, as opposed to the 211 found with the CDT method, is in accord with the results published by Franco et al. ${ }^{20}$

The finding of $M B L$ production being the highest among the Klebsiella spp. in the present study which is similar to the $31-51 \%$ rate recorded by Wattal et al. ${ }^{21}$ Similar findings were reported by Datta et al. ${ }^{22}$ and Gupta et al..$^{23}$ In our study, children of age 0-9 years made up $54.3 \%$ of the total number of patients with MBLproducing Enterobacteriaceae, corroborating a few publications that stated that children can harbor these organisms and act as their hosts. ${ }^{24,25}$

The Carba NP test is a newly introduced calorimetric test based on the enzymatic degradation of the $\beta$-lactam ring of the carbapenems. It is available commercially as well as producible in-house and has shown very good sensitivity (90-100\%) and specificity (up to $100 \%$ ) in the identification of carbapenemase producers among the Enterobacteriacea and other non-fermenting GNB. ${ }^{26,27}$ In this study, our in-house Carba NP test showed greater sensitivity than the other phenotypic tests in identifying MBL producers. Despite it being much cheaper than the Carba NP tests available on the market, the performance of our in-house test was on par with that of its commercial counterparts.

Although molecular methodologies are the gold standards for the identification of carbapenemase genes, phenotypic tests are gaining wider popularity because of their ready availability, less requirement for technical expertise, and cost effectiveness. Thus, it is imperative that any of the phenotypic test scan be made available for the routine detection of MBL-producing organisms, especially nosocomial pathogens, so as to strengthen infection control strategies and maintain good clinical practices, there by preventing the spread of these infections in hospitals.

\section{CONCLUSION}

The prevalence of MBL-producing GNB is increasing, threatening the health- 
care cost and clinical outcomes of patients worldwide and indicating the extensive overuse of carbapenems. Organisms that are resistant to carbapenems should be routinely screened for their production of MBL. Such measures,together with appropriate infection control practices and treatment strategies, will help toward preventing the spread of these infections. The detection of MBL producers requires active observation. Our inhouse Carba NP test was successful in identifying carbapenemase producers among GNB, with good sensitivity and specificity. Moreover, the DDST is a simple, easy, and cost-effective method that can be used even in small health laboratories in peripheral setups.

\section{Limitations}

Molecular methods were not used in the present study.

\section{ACKNOWLEDGMENTS}

I am thankful to Department of Science and Technology for providing funding support for the project from which this paper grew, we acknowledge the infrastructure and support of SVS Medical College and Hospital \& Palamur Bioscience Pvt.Ltd.

\section{CONFLICT OF INTEREST}

The authors declare that there is no conflict of interest.

\section{AUTHORS' CONTRIBUTION}

All the authors listed have made a substantial direct and intellectual contribution to the work, and approved it for the publication.

\section{FUNDING}

This study was supported by Department of Science and Technology under Women Scientist Scheme No. SR/WOS-A/LS-643/2016(G)

\section{DATA AVAILABILITY}

The datasets generated during current study are available from the corresponding author on reasonable request.

\section{ETHICS STATEMENTS}

Ethical clearance certificate (SVSMC/IEC/ Approval /No.05/2018-623) was taken from the institutional ethical committee of SVS medical college and Hospital.

\section{REFERENCES}

1. Pragasam AK, Vijayakumar S, Bakthavatchalam YD, et al Molecular characterization of antimicrobial resistance in pseudomonas aerugionasa and acinetobacter baumanii during 2014 and 2015 collected across India. Indian J Med Microbiol. 2016;34(4):433-441. doi: 10.4103/0255-0857.195376

2. Ramasubramanian V, Iyer V, Sewlikar S, Desai A. Epidemiology of healthcare acquired infection - An Indian perspective on surgical site infection and catheter related blood stream infection. Indian J Basic Appl Med Res. 2014:3(4):46-63

3. Praveen RM, Harish BN, Parija SC. Emerging carbapenem resistance among nosocomial isolates of klebsiella pneumonia in south india. Int J Pharma Biosci. 2010;1(2):1-11

4. Gupta V, Soni R, Jain N, Chander J. In vitro cost effective methods to detect carbapenemases in Enterobacteriaceae. J Lab Physicians. 2018;10(1):101105. doi: 10.4103/JLP.JLP_25_17

5. Butt T, Usman M, Ahmed RN $\bar{N}$, Saifl. Emergence of metallo beta lactamase producing Pseudomonas aeruginosa in Pakistan. J Pak Med Assoc. 2005;55(7):302-304

6. Navneeth BV, Sridaran D, Sahay D, Belwadi MRS. A preliminary study on metallo beta lactamase producing Pseudomonas aeruginosa in hospitalized patients. Indian J Med Res. 2002;116:264-267.

7. CLSI. PERFORMANCE standards for antimicrobial susceptibility testing Twentieth informational supplement, Clinical and Laboratory Standards Institute Doc. M100ED28- 2018

8. Vamsi KS, Ramamoorthy S, Murali TS, Singh M, Kabra V. Utility of Carba NP test (Inhouse/RAPIDEC Commercial Kit) in the Identification of Carbapenemase Producing Clinical Isolates in a Tertiary Care Hospital. J Clin Diagnostic Res. 2019;13(12):19-22 doi: 10.7860/ JCDR/2019/42780.13375

9. Yong D, Lee K, Yum JH, Shin HB, Rossolini GM, Chong $Y$. Imipenem-EDTA disc method for differentiation of Metallo-beta- lactamase -producing clinical isolates of pseudomonas spp. and Acinetobacter spp. J Clin Microbiol. 2002;40(10):3798-3801. doi: 10.1128/ JCM.40.10.3798-3801.2002

10. Lee K, Lim YS, Yong D, Yum JH, Chong Y. Evaluation of the Hodge test and the imipenem-EDTA double-disk synergy test for differentiating metallo- $\beta$-lactamaseproducing isolates of Pseudomonas spp. and Acinetobacter spp. J Clin Microbiol. 2003;41(10):46234629. doi: 10.1128/JCM.41.10.4623-4629.2003

11. Sachdeva R, Sharma B, Sharma R. Evaluation of different phenotypic tests for detection of metallo$\beta$-lactamases in imipenem-resistant Pseudomonas aeruginosa. J Lab Physicians. 2017;9(4):249-253. doi: 10.4103/JLP.JLP_118_16

12. Pasteran F, Veliz O, Rapoport M, Guerriero L, Corso A. Sensitive and specific modified Hodge test for KPC and metallo- $\beta$-lactamase detection in Pseudomonas 
aeruginosa by use of a novel indicator strain, Klebsiella pneumoniae ATCC 700603. J Clin Microbiol. 2011;49(12):4301-4303. doi: 10.1128/JCM.05602-11

13. Pasteran F, Veliz, Faccone $D$, et al. A simple test for the detection of KPC and metallo- $\beta$-lactamase carbapenemase-producing Pseudomonas aeruginosa isolates with the use of meropenem disks supplemented with aminophenylboronic acid, dipicolinic acid and cloxacillin. Clin Microbiol Infect. 2011;17(9):1438-1441. doi: 10.1111/j.1469-0691.2011.03585.x

14. Picao RC, Andrade SS, Nicoletti AG, et al. Metallo$\beta$-lactamase detection: comparative evaluation of double-disk synergy versus combined disk tests for IMP-, GIM-, SIM-, SPM-, or VIM-producing isolates. J Clin Microbiol. 2008;46(6):2028-2037. doi: 10.1128/ JCM.00818-07

15. Hussein HN, Al-Mathkhury JFH, Sabbah AM. Imipenem resistant Acinetobacter baumannii isolated from patients and hospitals environment in Baghdad. Iraqi Journal of Science. 2013;54(4):803-812.

16. Walsh TR, Toleman MA, Poirel L, Nordmann P. Metallo- $\beta$-lactamases: The quiet before the storm? Clin Microbiol Rev. 2005;18(2):306-325. doi: 10.1128/ CMR.18.2.306-325.2005

17. Hemalatha V, Sekar U, Kamat V. Detection of metallo betalactamase producing Pseudomonas aeruginosa in hospitalized patients. Indian J Med Res. 2005;122(2):148-152. PMID: 16177473

18. Perry JD, Naqvi SH, Mirza IA, et al. Prevalence of faecal carriage of Enterobacteriaceae with NDM-1 carbapenemase at military hospital in Pakistan,and evaluation of two chromogenic media. J Amtimicrob Chemother. 2021;66(10):2288-2294. doi: 10.1093/jac/ dkr299

19. Khosravi Y, Loke MF, Chua EG, Tay ST, Vadivelu J. Phenotypic detection of metallo- $\beta$-lactamase in imipenem resistant pseudomonas aeruginosa. Scientific World Journal. 2012;2012.654939

20. Franco BE, Altagracia Martinez M, Sanchez Rodriguez
MA, Wertheimer Al. The determinants of the antibiotic resistance process. Infect Drug Resist. 2009;2:1-11. doi: 10.2147/IDR.S4899

21. Wattal C, Goel N, Oberoi JK, Raveendran R, Datta $\mathrm{S}$, Prasad KJ. Surveillance of multidrug resistant organisms in tertiary care hospital in Delhi, India. J Assoc Physicians India. 2010;58:32-36

22. Datta P, Gupta V, Garg S, Chander J. Phenotypic method for differentiation of carbapenemases in Enterobacteriaceae: Study from North India. Indian J Pathol Microbiol. 2012;55(3):357-360. doi: 10.4103/0377-4929.101744

23. Gupta E, Mohanty S, Sood S, Dhawan B, Das BK, Kapil A. Emerging resistance to carbapenems in a tertiary care hospital in north India. Indian J Med Res. 2006;124:(1)95-98. PMID: 16926463

24. Viau RA, Hujer AM, Marshall SH, et al. "Silent" dissemination of Klebsiella pneumoniae isolates bearing $K$. pneumoniae carbapenems in a long-term care facility for children and young adults in Northeast Ohio. Clin Infect Dis. 2012;54(9):1314-1321. doi: 10.1093/cid/cis036

25 Yaffee AQ, Roser L, Daniels K, et al. Notes from the field: Verona integron-encoded metallo-beta-lactamaseproducing carbapenem-resistant Enterobacteriaceae in a neonatal and adult intensive care unit-Kentucky, 2015. MMWR Morb Mortal Wkly Rep. 2016;65(7):190. doi: 10.15585/mmwr.mm6507a5

26. Tijet N, Boyd D, Patel SN, Mulvey MR, Melano RG. Evaluation of the Carba NP test for rapid detection of carbapenemase-producing Enterobacteriaceae and Pseudomonas aeruginosa. Antimicrob Agents Chemother. 2013;57(9):4578-4580. doi: 10.1128/ AAC.00878-13

27. Garg A, Garg J, Upadhyay GC, Agarwal A, Bhattacharjee A. Evaluation of the Rapidec Carba NP Test Kit for Detection of Carbapenemase-Producing GramNegative Bacteria. Antimicrob Agents Chemother. 2015;59(12):7870-7872. doi: 10.1128/AAC.01783-15 